\title{
Surface Modification with Silane Coupling Agent on Tensile Properties of Natural Fiber Composite
}

\author{
Willy Artha Wirawan ${ }^{a}$, Sofyan Arief Setyabudi ${ }^{b}$, Teguh Dwi Widodo ${ }^{c}$, Moch. Agus Choiron ${ }^{c}$ \\ a'Mechanical Engineering Department, Brawijaya University, Malang, Indonesia \\ Telephone +62-341-554291, 587711, fax +62-341-554291 \\ e-mail: willymadiun93@gmail.com
}

\begin{abstract}
Biocomposite is an innovation of renewable material in engineering made from the bark fiber of waru (Hibiscus tiliaceus, the bark is environmentally friendly and has the potential to be developed. The purpose of this study is to modify biocomposite by adding methacryloxypropyltrimethoxysilane-coupling agent on waru bark fiber (Hibiscus tiliaceus) as an effort to improve tensile properties. Waru bark fibers, as reinforcement, were prepared by alkali process using $6 \% \mathrm{NaOH}$ solution for 120 minutes and then added $0.75 \%$ coupling agent and ordered using continous fibers with $0 \% 0^{\circ}, 0 \% 0^{\circ}$ and $45 \% 45^{\circ}$ orientation. After that, the Biocomposites were formed with a polyester matrix using Vacuum Pressure Resin Infusion (VAPRI) method. The results of SEM tested showed the quality improvement of the bonds bringing significant impact on the tensile properties of the waru bark biocomposite. On the continuous fiber $0 \% 90^{\circ}$ orientated showed that the highest strength was 401.368 MPa, while biocomposites with $45 \% 45^{\circ}$ orientation has lowest tensile strength of $65.243 \mathrm{MPa}$.
\end{abstract}

Keywords: Natural Fiber Composite; Waru bark; Silane Coupling Agent; Tensile strength

\section{INTRODUCTION}

Natural fibers have now been widely used as reinforcements in the making of composites as they are more environmentally friendly compared to synthetic fibers [1]. Natural fibers have many advantages such as low price, abundant of amount, lightweight, high strength, and biodegradable [2]. Therefore, it has great potential to be developed as reinforcement material for polymer composites [3].
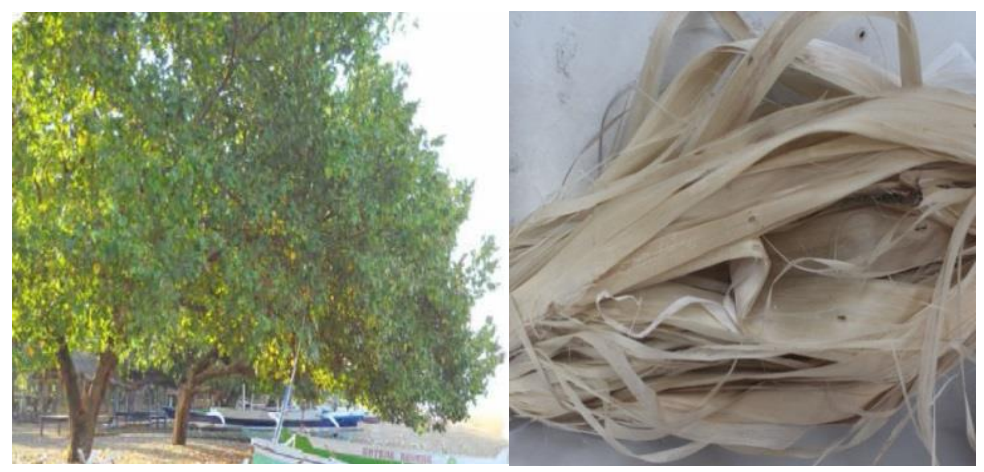

Figure 1.1 (a) Hibiscus tiliaceus and (b) Hibiscus fibers

Waru (Hibiscus tiliaceus) in Figure 1 is a plant that widely found in Indonesia. People uses the trees as the material for making vessel ropes because its strength and toughness. Hence, it can be developed as reinforcement in the manufacture of polymer 
composites [4] [5]. The problem often arises in the manufacture of natural fibers based composites are the debonding that causes composite strength decrease [6]. One the method to overcome this problem is by chemical treatments using $\mathrm{NaOH}$ solution and addition of silane coupling agent. This method improve the adhesion force and entanglement bond, hence improving the compatibility of polymer matrix and natural fiber [7]. The silane will react with the cellulose on the fiber surface and bind the matrix [8].

The presence of hydroxyl group $\mathrm{OH}$ in natural fibers causes the waru bark fibers to be hydrophilic. It causes poor bonding quality to the polymer matrix [9]. Surface modification is necessary reducing the hydrophilic properties of the waru bark fibers, hence increasing its compatibility. The effort of this study is to improve tensile properties of waru bark fiber (Hibiscus tiliaceus) biocomposites by surface modification using methacryloxypropyltrimethoxysilane-coupling agent. This coupling agent is belong to anhybride group that can react with the surface hydroxyl groups of natural fiber, and successfully applied to organic filler reinforced polymer composite.

\section{Methodology}

The waru bark fiber was supplied by waru farmers in Tulungagung, Indonesia. Its specification shows in the Table 2.1. While The matrix polyester 157 is supplied from PT Justus Kimia Raya Surabaya and the chemical specification of the matrix is shows in Table 2.2.

Table 2.1 Chemical Specification of the Fibers from Waru Bark

\begin{tabular}{ll}
\hline Properties & Composition \\
\hline Raw protein & 17.08 \\
Ether extract & 3.45 \\
Raw fibers & 22.77 \\
Ash $(\%)$ & 10.79 \\
Carbohydrate & 45.91 \\
Tannin $(\%)$ & 8.93 \\
Saponins $(\mathrm{mg} / \mathrm{g})$ & 12.90 \\
Cellulose & 24.22 \\
\hline
\end{tabular}

Table 2.2 Chemical Specification of the Polyester Matrix 157

\begin{tabular}{lll}
\hline Mechanical Properties & Quantity & Unit \\
\hline Specific gravity & 1.4 & $\mathrm{gr} / \mathrm{cm}^{3}$ \\
Hardness & 40 & - \\
Heat distortion temperature & 70 & ${ }^{\circ} \mathrm{C}$ \\
Water absorption (room temperature) & 0.188 & $\%(24 \mathrm{jam})$ \\
Flexural Strength & 0.446 & $\%(7 \mathrm{hari})$ \\
Flexural Modulus & 9.4 & $\mathrm{Kg} / \mathrm{mm}^{2}$ \\
Tensile strength & 300 & $\mathrm{Kg} / \mathrm{mm}^{2}$ \\
Elasticity modulus & 5.8 & $\mathrm{Kg} / \mathrm{mm}^{2}$ \\
Elongation & 300 & $\mathrm{Kg} / \mathrm{mm}^{2}$ \\
\hline
\end{tabular}

The surface modification of the waru bark fibers was carried out by a chemical treatment using $\mathrm{NaOH}$ solution with Methacryloxypropyl-trietoxysilane silane-coupling agent addition originated from Dow Corning. This coupling agent has specific gravity and viscosity of 1.03 and $5 \mathrm{~mm}^{2} / \mathrm{s}$, respectively. The chemical structure of silane-coupling agent can be seen in Figure 2.1. 


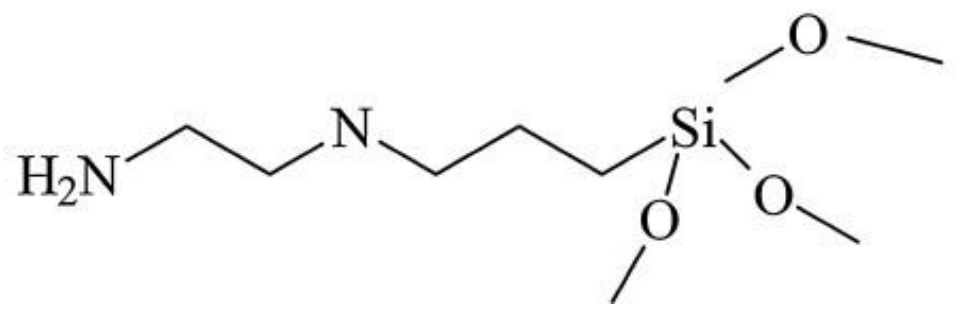

Figure 2.1 The chemical structure of Methacryloxypropyltrietoxysilane [10]

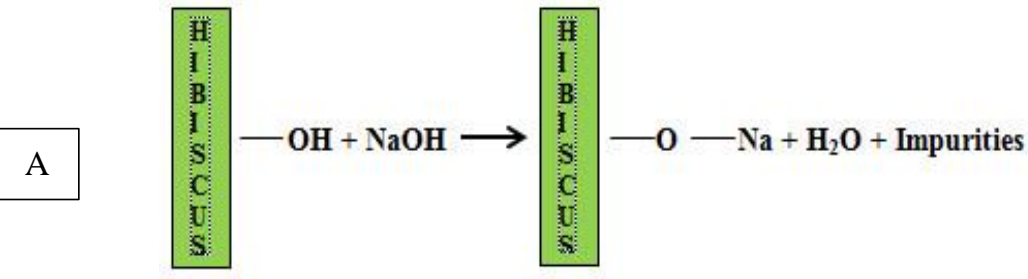

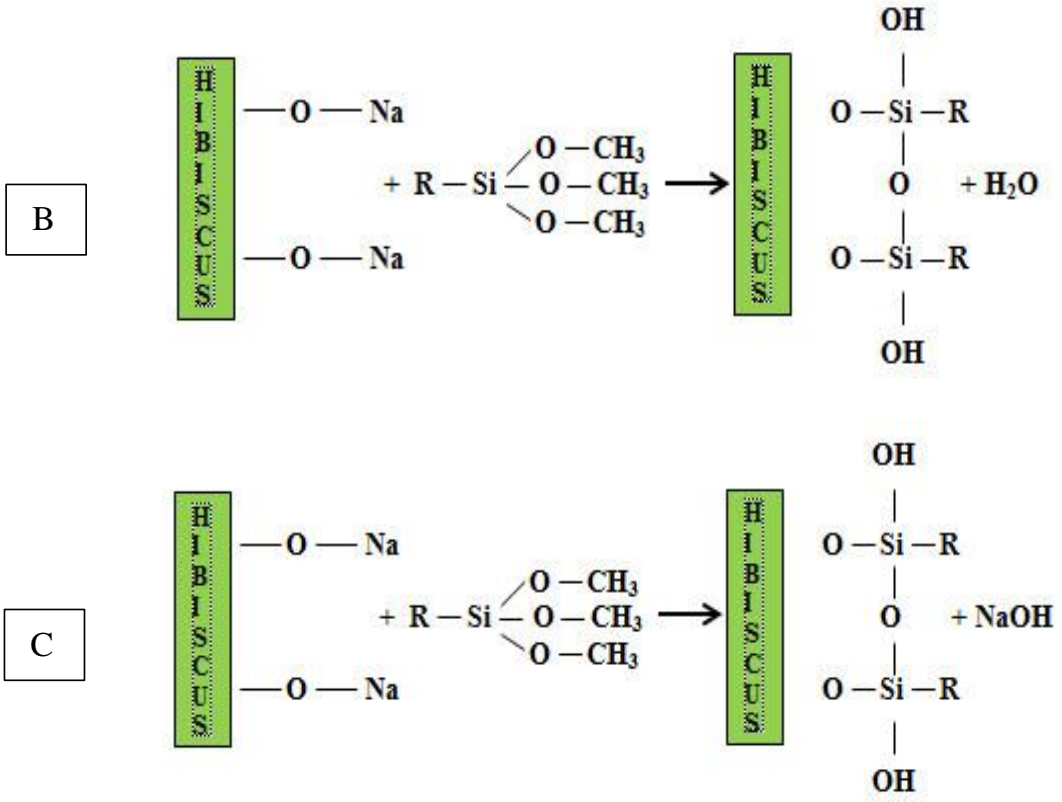

Figure 2.2 The chemical structure (a) alkali treatment reaction (b) silane treatment reaction (c) alkali-silane treatment reaction

A chemical treatments of waru bark fiber have done using $6 \% \mathrm{NaOH}$ solution for 120 minutes. After that, the bark was washed with water until the $\mathrm{pH}$ reached 7 (neutral) and then it dried at the room temperature for six days.

The addition of The coupling agent was done by immersing the fibers using Methacryloxy-propyltrimethoxysilane solution at $0.75 \%$ concentration and the $\mathrm{pH}$ of the solution was regulated of $3.4-4.5$. It was conducted for 4 hours. Then the fibers were washed and dried at an oven at $70^{\circ} \mathrm{C}$.

The composite strength has been investigated by using universal testing machine model JTM-UTS510 tensile test at $0.2 \mathrm{~mm} / \mathrm{s}$ of speed. The specimens were made according to ASTM D638-03 standard. The surface morphology of the fiber has been known by microstructural observation using Scanning Electron Microscopy (SEM) type VEGA 3 TESCAN. 
The composite manufacture process was conducted by Vacuum Assisted Resin Infusion (VARI) method is shown in Figure 2.3.

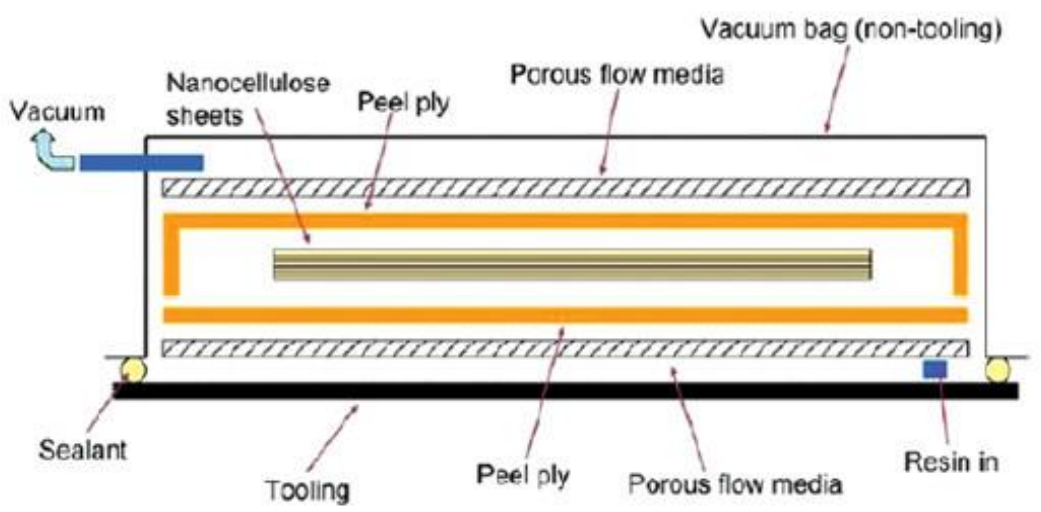

Figure 2.3. The Systematic Diagram of VARI [11]

Table 2.3 Treatment of Fibers

\begin{tabular}{|c|c|c|}
\hline $\begin{array}{l}\text { Treatment } \\
\text { Type }\end{array}$ & Code & Description \\
\hline Untreated & SS & Fiber without treatment \\
\hline \multirow[t]{3}{*}{ Alkali (SN) } & SN 0-0 & Fiber treated with alkali continous fiber composite \\
\hline & SN 0-90 & Fiber treated with alkali orientation $0-90$ \\
\hline & SN $45-45$ & Fiber treated with alkali orientation $45-45$ \\
\hline \multirow[t]{3}{*}{$\begin{array}{l}\text { Alkali Silane } \\
\text { (SSN) }\end{array}$} & SSN 0-0 & $\begin{array}{l}\text { Fiber treated with alkali and silane continous fiber } \\
\text { composite }\end{array}$ \\
\hline & SSN 0-90 & Fiber treated with alkali and silane orientation $0-90$ \\
\hline & SSN 45-45 & Fiber treated with alkali and silane orientation $45-45$ \\
\hline
\end{tabular}

\section{ResUlt AND Discussion}

\subsection{Interface Morphology}

The SEM result on Figure 3.1 shows the density improvement of surface. Figure 3.1a shows that untreated bark (SS) has rougher surface because it has more cellulose and hemicellulose content [2]. Whereas Figure 3.1b shows that the fiber interface with alkali treatment (SN) is proven cleaner and has a flatter and smoother fiber texture. The alkali treatment is very effective on reducing cellulose, lignin, and hemicellulose content [12].

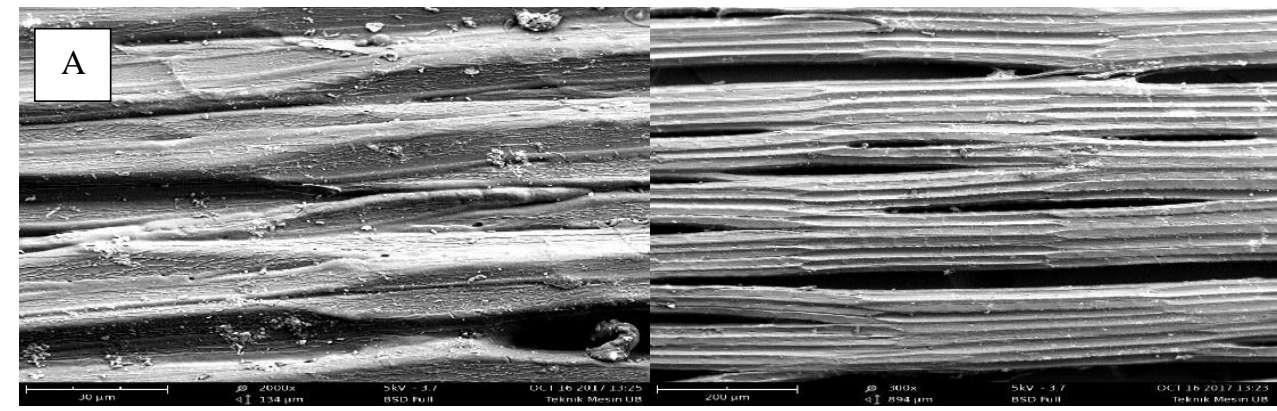

Figure 3.1 (a) Untreated SS (b) Alkali Treatment SN (c) Alkali and Silane Treatment SSN 

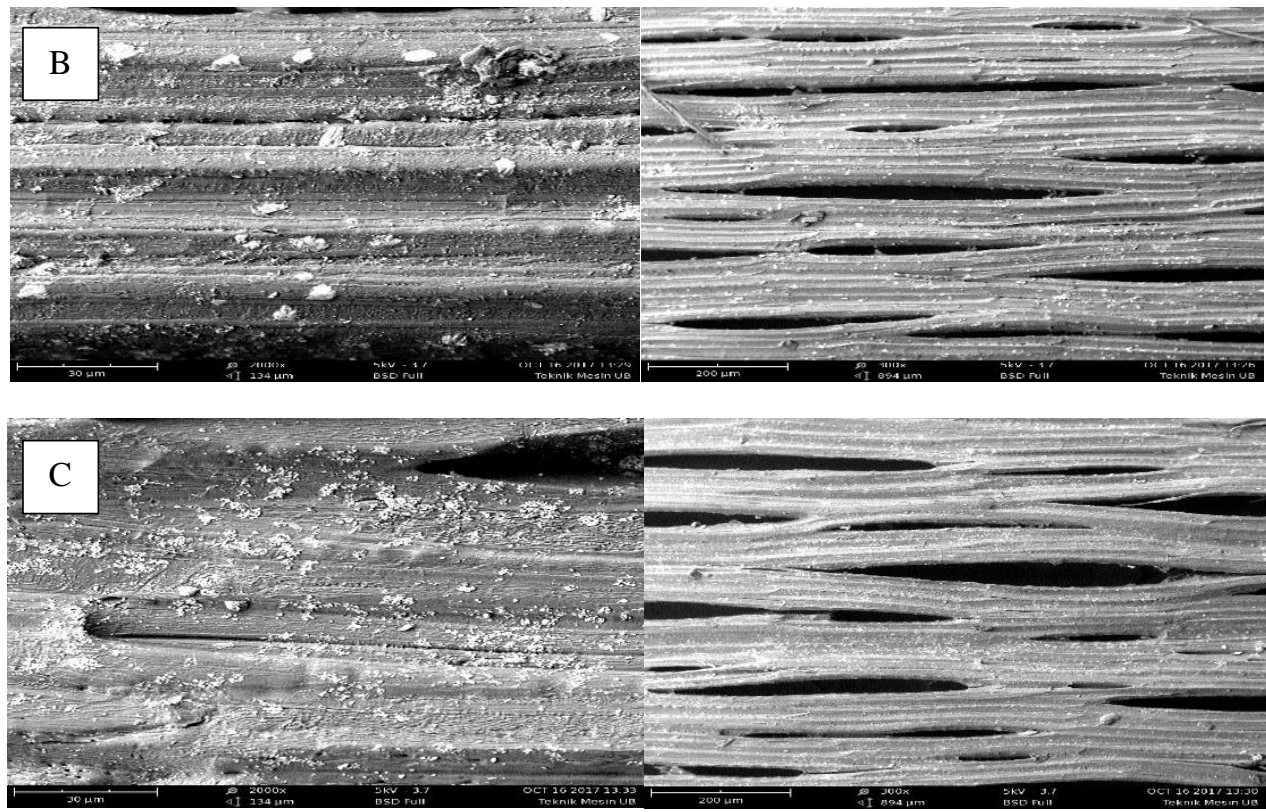

Figure 3.1 (a) Untreated SS (b) Alkali Treatment SN (c) Alkali and Silane Treatment SSN (continued)

Fibers with alkaline and silane treatment (SSN) shows a better surface morphology [10]. The fiber surface becomes very clean, flat, dense, and very smooth compared to the untreated one (SS) and alkali treated (SN) surfaces. With better interfaces, it is possible to have compatibility between the bark fiber and polymer matrix [12]. The matrix and the bark fibers will make a good binding, hence the biocomposite can receive the load evenly and provide a very significant impact to increase its tensile strength [13]

\subsection{Tensile Properties}

The surface modification of the waru bark fibers has a significant effect on the tensile strength of the biocomposite and it is can be seen in Figure 3.2, 3.3 and 3.4.

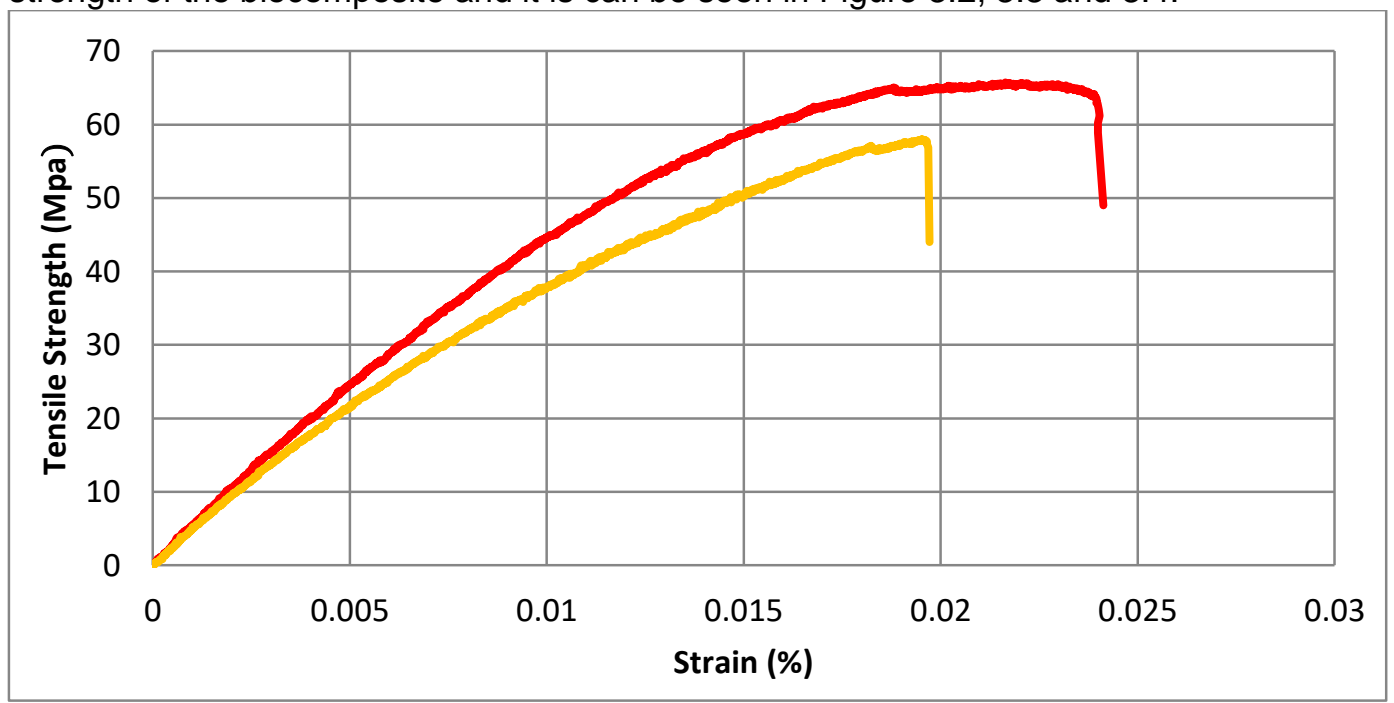

Figure 3.2 Strain-Stress (a) Fiber Treated with Alkali Orientation 45-45

(b) Fiber Treated with Alkali and Silane Orientation 45-45

Figure 3.2 shows the biocomposite strain treated by the alkali (SN) and alkali silane (SSN) form a 45-45 orientation angle of the fiber arrays. It can be seen in Figure 3.2 that biocomposite treated with alkali silane has higher strength and strain than biocomposite 
treated with alkali, with $65.24 \mathrm{Mpa} 0.023 \%$ and $58.005 \mathrm{Mpa} 0.023 \%$, respectively. The biocomposite on 45-45 oriented has higher strain compared to unidirectional composites on $0-90$ orientation, meanwhile the strength is lower [14].

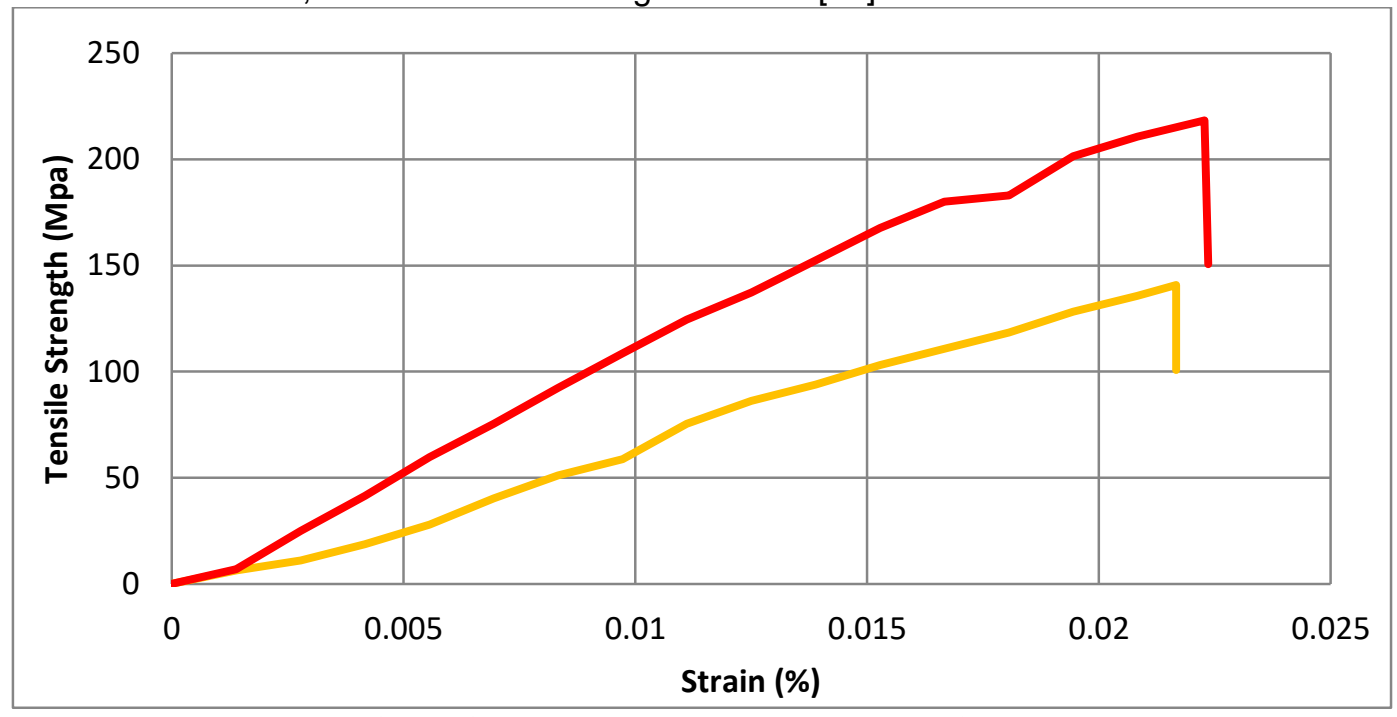

Figure 3.. Strain-Stress (a) Fiber Treated with Alkali Orientation 0-90

(b) Fiber Treated with Alkali and Silane Orientation 0-90

Figure 3.3 shows the biocomposite strain treated by the alkali (SN) and alkali silane (SSN) form a 90-90 orientation angle of the fiber arrays. It can be seen in Figure 3.3 that biocomposite treated with alkali silane has higher strength and strain than biocomposite treated with alkali, with $218.246 \mathrm{Mpa} 0.22 \%$ and $140.861 \mathrm{Mpa} 0.021 \%$, respectively. The biocomposite on $0-90$ oriented has higher strain compared to composites on $45-45$ orientation [14].

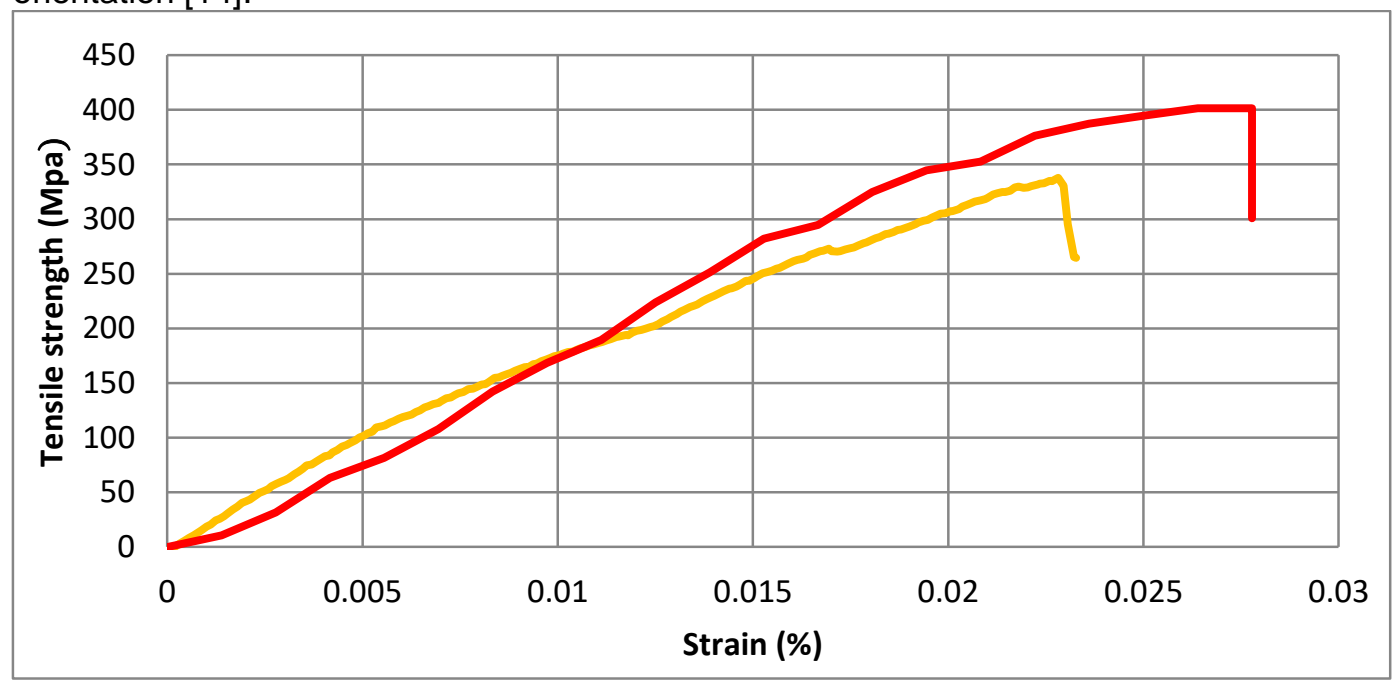

Figure 3.4 Strain-Stress (a) Fiber Treated with Alkali Continous Fiber Composite (b) Fiber Treated with Alkali and Silane Continous Fiber Composite

Figure 3.4 shows the biocomposite strain treated by the alkali (SN) and alkali silane (SSN) form a unidirectional fiber arrays. It can be seen in Figure 3.4 that biocomposite treated with alkali silane has higher strength and strain than biocomposite treated with alkali, with $401.368 \mathrm{Mpa} 0.027 \%$ and $3387.78 \mathrm{Mpa} 0.022 \%$, respectively. The unidirectional biocomposite has the highest strength. Because it has longitudinal direction toward uniaxial load, hence it minimize the shear failure [14]. 


\section{CONCLUSION}

Fiber treatment using alkali and silane improve the surface, hence increasing tensile strength of biocomposite. Biocomposites with unidirectional alkaline silane treatment have the highest tensile strenght of $401.368 \mathrm{MPa}$, while the lowest tensile strength is obtained on $45^{\circ} / 45^{\circ}$ orientation angle biocomposites of $65.243 \mathrm{MPa}$.

\section{REFERENCES}

[1] Kumari, M., Kumar, R., \& Kumar, V. (2014). Surface modification of cellulose using silane coupling agent. Carbohydrate Polymers, 111, 849-855. https://doi.org/10.1016/i.carbpol.2014.05.041

[2] Xue. Li., \& Canada, A. (2007). Chemical Treatments of Natural Fiber for Use in Natural Fiber-Reinforced Composites: A Review Chemical Treatments of Natural Fiber for Use in Natural Fiber-Reinforced Composites: A Review, (May 2014). https://doi.org/10.1007/s10924-006-0042-3

[3] Nishino T. (2004). Natural Fiber Sources, In: Bailie C, editors, Green composites Polymer composites and the environment, England, Woodhead Publishing Limited, pp:49

[4] Malkapuram R, Kumar V, Negi YS. (2009). Recent development in natural fiber reinforced polypropylne composites, Journal of Reinforced Plastics and Composities, 8 (10), 1169-1189

[5] Palungan, M. B., Soenoko, Y. S. Irawan, A. Purnowidodo (2015). Mechanical properties of king pineapple fiber (Agave Cantula Roxb) as $A$ result of fumigation treatment. Australian journal of basic and applied sciences 9:560-63

[6] Akil H.M., Omar., Mazuki A.A.M., Safiee S., Ishak Z.A.M., Abu Bakar A. 2011. Kenaf Fiber Reinforced Composites: A review, Material and design, 32:4107-4121

[7] Dittenber D.B. and H.V.S. Ganga Rao. 2012. Critical review of recent publications on use of natural composites in infrastructure. Composites part A43 (8):1419-29

[8] Hermanson G.T., 2008. Bioconjugate Techniques, Second edition, Elsevier's Science \&Technology Rights. United Kingdom

[9] Islam, M. R. \& Beg, M. D. H. (2010). Effect Of Coupling Agent On Mechanical Properties Of Composite From Kenaf and Rcycled Polypropylne. National Conference In Mechanical Engineering Research and Postgraduate Studies. Malaysia: University Malaysia Pahang, pp 871-875

[10] Raharjo, W. W., Soenoko, R., Irawan, Y. S., \& Suprapto, A. (2017). The Influence of Chemical Treatments on Cantala Fiber Properties and Interfacial Bonding of Cantala Fiber / Recycled High Density Polyethylene (rHDPE). Journal of Natural Fibers, O(0), 1-14. https://doi.org/10.1080/15440478.2017.1321512

[11] Thakur, K. V., Thakur, K. M., Gupta, K. R. (2014). Review: Raw Natural Fiber-Based Polymer Composites. International Journal of Polymer. 19: 256-271

[12] Zhou F., G. Cheng and B. Jiang. (2014). Effect of silane treatment on microstructure of sisal fibers, Applied Surface Science 292:806-12

[13] Gan, H. L., L. Tian, and C.H.Yi. (2014). Effect of sisal fiber surface treatments on sisal fiber reinforced polypropylene (PP) composites. Advance Materials Research 906:167-77

JEMMME | Journal of Energy, Mechanical, Material, and Manufacturing Engineering 
JEMMME, Vol.2, No. 2, November 2017

ISSN 2541-6332

e-ISSN 2548-4281

[14] Setyabudi, S. A., Makabe, C., Fujikawa, M., Tohkubo, T. (2011). Fatique and Static Fracture of Machineable C/C Composites. Journal of Solid Mechanichs and Materials Engineering Vol. 5, No. 11, 640-654. 